\title{
Alpha-tricalcium phosphate cement in the reconstruction of bone defects in rats ${ }^{1}$
}

\author{
Cimento de alfa-tricálcio-fosfato na reconstrução de defeitos ósseos em ratos
}

\begin{abstract}
João Gabriel Souza Pinto", Bruno Tochetto Primo", Humberto Thomazi Gassen", Sérgio Augusto Quevedo Miguens Júnior ${ }^{\text {III, }}$ Pedro Antonio González Hernández ${ }^{\mathrm{III}}$, Luis Alberto dos Santos ${ }^{\mathrm{IV}}$, Aurelício Novaes Silva Júnior ${ }^{\mathrm{V}}$

${ }^{1}$ Research performed at the Animal Experimentation Unit, Research Center, Department of Veterinary Medicine, School of Veterinary Medicine, Lutheran University of Brazil (ULBRA), Canoas-RS, Brazil. Part of the dissertation of the author. Tutor: Aurelicio Novaes Silva Jr.

${ }^{\text {I }}$ Fellow Master degree, Department of Oral and Maxillofacial Surgery, School of Dentistry, ULBRA, Canoas-RS, Brazil. Main author. Responsible for conception, design, intellectual and scientific content of the study.

${ }^{\text {II }}$ Fellow Master degree, Department of Oral and Maxillofacial Surgery, School of Dentistry, ULBRA, Canoas-RS, Brazil. Surgical procedures and manuscript writing.

${ }^{\mathrm{III}} \mathrm{PhD}$, Associate Professor, Department of Oral Maxillofacial Surgery, School of Dentistry, ULBRA, Canoas-RS, Brazil. Acqusition and interpretation of data. Critical revision.

IV PhD, Full Professor, Department of Materials, School of Mechanical Engineering, UFRGS, Porto Alegre-RS, Brazil. Supervised all phases of the study and critical revision.

${ }^{\mathrm{v}} \mathrm{PhD}$, Associate Professor, Department of Oral and Maxillofacial Surgery, School of Dentistry, ULBRA, Canoas-RS, Brazil. Responsible for conception and critical revision of the study.
\end{abstract}

\section{ABSTRACT}

Purpose: To evaluate the ability of a mixture of $\alpha$-TCP and autogenous bone (AB) vs. $\alpha$-TCP alone and AB alone to promote new bone formation and tissue repair in bone defects. Methods: Bone defects surgically created in 15 male Wistar rats were divided into four groups: Group I (AB), Group II $(\alpha-\mathrm{TCP})$, Group III $(\alpha-\mathrm{TCP}+\mathrm{AB}$ assessed by light microscopy), and Group IV ( $\alpha$-TCP+AB assessed by scanning electron microscopy). Bone repair findings were assessed at 30, 60, and 120 days postoperatively. Results: The histological findings obtained in Groups I $(p=0.459)$, II ( $p=0.368)$, and III $(p=0.459)$ and at 30 days $(p=0.717), 60$ days $(p=0.717)$, and 120 days $(\mathrm{p}=0.779)$ did not show statistically significant differences. Scanning electron microscopy revealed direct contact between the $\alpha-\mathrm{TCP}+\mathrm{AB}$ implant and the bone tissue at 120 days. Conclusion: The $\alpha-\mathrm{TCP}$ implant is effective alternative bone substitutes for the treatment of critical size bone defects.

Key words: Bone Substitutes. Bone Transplantation. Biocompatible Materials. Rats.

\section{RESUMO}

Objetivo: Avaliar a capacidade da mistura de $\alpha$-TCP e osso autógeno (OA) Vs somente $\alpha$-TCP e somente OA em promover a neoformação óssea e reparo tecidual em defeitos ósseos. Métodos: Foram criados cirurgicamente defeitos ósseos em 15 ratos Wistar machos, distribuídos em quatro grupos: Grupo I (OA), Grupo II ( $\alpha$-TCP), Grupo III ( $\alpha$-TCP + OA avaliado por microscopia de luz) e Grupo IV ( $\alpha$-TCP + OA avaliado por microscopia eletrônica de varredura). Os resultados da reparação óssea foram avaliados em 30, 60 e 120 dias. Resultados: os achados histológicos obtidos nos grupos I $(p=0,459)$, II $(p=0,368)$ e III $(p=0,459)$ e aos 30 dias $(p=$ $0,717), 60$ dias $(p=0,717)$, e 120 dias $(p=0,779)$ não apresentaram diferenças estatisticamente significativas. A análise por microscopia eletrônica de varredura revelou contacto direto entre o implante de $\alpha$-TCP + AO e o tecido ósseo aos 120 dias. Conclusão: O implante de $\alpha$-TCP é alternativa eficaz como substitutos ósseos para o tratamento de defeitos ósseos de tamanho crítico.

Descritores: Substitutos Ósseos. Enxerto Ósseo. Materiais Biocompatíveis. Ratos. 


\section{Introduction}

The search for an ideal implant material, biocompatible and able to promote tissue repair, has been a key issue for researchers and surgeons interested in hastening the repair of bone fractures and the reconstruction of critical size bone defects ${ }^{1}$.

Calcium phosphate cements (CPCs) have been widely used for facial reconstruction because of some important characteristics: biocompatibility (their chemical composition is similar to that of mineral bone); bioactivity; osteoconductivity; easy handling and molding (and therefore the possibility of intraoperative preparation and optimal adaptation to the defect); direct contact with bone tissue since the first stages of implantation; and in situ-setting ability, without heating, which prevents tissue necrosis at the implantation site ${ }^{2-4}$. Jackson and Yavuzer ${ }^{5}$ have considered CPC to be the most promising and well-tolerated alloplastic biomaterial currently available.

Since CPCs were first described, and due to their potential biomedical applications, these cements have been constantly evaluated and improved. Several studies have been designed to test different material combinations, and a new type of CPC, namely alpha-tricalcium phosphate ( $\alpha$-Ca3(PO4)2, $\alpha$-TCP), has recently been shown to promote new bone formation and calcification more rapidly when compared with conventional $\mathrm{CPC}^{6}$.

Several methods have been used to evaluate the performance of different implant materials. Among these, scanning electron microscopy (SEM) has been used to assess CPCs and has evidenced adequate biocompatibility and osteoconductivity properties associated with this material, with absence of inflammatory reaction and presence of new bone formation at the implant-bone interface ${ }^{7,8}$.

The objective of this study was to assess the ability of a mixture of $\alpha$-TCP and autogenous bone (AB) vs. $\alpha$-TCP alone and $\mathrm{AB}$ alone to promote new bone formation and tissue repair in bone defects, using light microscopy and scanning electron microscopy (SEM).

\section{Methods}

The research protocol of the present study was approved by the Research Ethics Committee at University Luterana of Brazil (ULBRA), Canoas (protocol no. 2006-014A).

The $\alpha$-TCP cement used in the present study was prepared in the Laboratory of Biomaterials (Labiomat) at Federal University of Rio Grande do Sul (UFRGS), Porto Alegre, Brazil $^{2,9}$. The cement is composed of $85 \% \alpha$-TCP, $15 \%$ calcium sulfate, and a liquid accelerator containing $2.5 \% \mathrm{Na}_{2} \mathrm{HPO}_{4}$. The resulting CPC presents a dual-setting hydraulic system, and was therefore named dual-setting calcium phosphate hydraulic cement (DSCPHC). The initial setting is obtained by the hydration of calcium sulfate $\left(\mathrm{CaSO}_{4} \cdot 1 / 2 \mathrm{H}_{2} \mathrm{O}+\mathrm{H}_{2} \mathrm{O} \square \mathrm{CaSO}_{4} \cdot 2 \mathrm{H}_{2} \mathrm{O}\right)$, and the final setting is obtained by the hydration of $\alpha$-TCP $\left[\alpha-\mathrm{Ca}_{3}\left(\mathrm{PO}_{4}\right)_{2}+\right.$ $\left.\mathrm{H}_{2} \mathrm{O} \square \mathrm{Ca}_{9}\left(\mathrm{HPO}_{4}\right)\left(\mathrm{PO}_{4}\right)_{5} \mathrm{OH}\right]$, which produces a calcium-deficient hydroxyapatite phase similar to biological hydroxyapatite.

Fifteen male Wistar rats (Rattus novergicus albinus), aged approximately 180 days, clinically healthy, with a mean weight of 300 grams at surgery, were selected for this study. The animals were kept in individual cages, under normal laboratory conditions (room temperature at $25^{\circ} \mathrm{C}, 12$-hour light/dark cycle), and received food and water ad libitum.

Bone defects were surgically created in the femurs of the 15 rats and were divided into four groups: Group I (AB), Group II $(\alpha-\mathrm{TCP})$, Group III $(\alpha-\mathrm{TCP}+\mathrm{AB})$, and Group IV $(\alpha-\mathrm{TCP}+\mathrm{AB})$. Groups III and IV were identical in terms of the material under investigation, however Group IV was assessed using SEM, whereas the other three groups were assessed using light microscopy.

Prior to surgery, anesthesia was induced with intramuscular tiletamin-zolazepam $20 \mathrm{mg} / \mathrm{kg}$ (Zoletil ${ }^{\circledR} 50 \mathrm{mg}$ ), at a dose of $0.4 \mathrm{ml} / \mathrm{kg}$, supplemented with half the initial dose $(0.2 \mathrm{ml} /$ $\mathrm{kg}$ ) whenever necessary.

A titanium surgical mesh was designed so as to produce standardized, equidistant bone perforations. A total of four bone perforations were made on the lateral surface of the right and left femurs of each rat (two on each side) using a 3.8-mm trephine bur $\left(\right.$ Promm $^{\circledR}$, Porto Alegre-RS, Brazil) and an electric motor (Driller BLM600 ${ }^{\circledR}$, Sao Paulo-SP, Brazil) coupled to a handpiece $\left(\mathrm{KAVO}^{\circledR}\right.$, Biberach, Germany). Perforations were made so as to create a critical size defect and avoid postoperative femoral fractures, as recommended by Le Guehennec et al. ${ }^{10}$ and Hollinger et al. ${ }^{11}$. The defect models presented a standard depth, determined by rupture of the cortical bone.

Two perforations were made on the right femur of rats: the first was made in the proximal portion of the shaft and filled with particulate $\mathrm{AB}$ harvested from the contralateral femoral defect (Group I); the second was made in the distal end of the shaft, with the aid of the surgical mesh, and filled with $\alpha$-TCP alone until the cavity was completely filled and until transition of the material from the aqueous into the solid phase was observed (Group II). The same procedures were followed to produce the third and fourth perforations on the left femurs. These perforations were filled with $\alpha$-TCP combined with particulate AB harvested from the contralateral femoral defect $(\alpha-\mathrm{TCP}+\mathrm{AB})$ at a $1: 1$ ratio (Groups III and IV).

Animals were killed 30, 60, and 120 days postoperatively with an overdose of the anesthetic solution (intramuscular injection of tiletamin-zolazepam). Bone blocks containing the defects and implants were removed using a Commet ${ }^{\mathbb{B}}$ diamond disc, fixed in $10 \%$ formalin, decalcified and then prepared and numbered for histological analysis. Histological samples obtained from Groups I, II and III were submitted to microscopic analysis under light microscopy, whereas samples obtained from Group IV were submitted to SEM analysis.

Microscopic analysis of the histological slides was descriptive and assessed the presence or absence of new bone formation according to the morphological criteria established by Takeda ${ }^{12}$. Other bone repair variables such as bone necrosis, bone resorption and inflammatory infiltrate were also observed during image analysis, but only data on new bone formation were statistically analyzed. A total of 45 histological slides were assessed.

The following bone formation scores were assigned to each sample in Groups I, II, and III during microscopic analysis: score 0 , no bone formation; score 1 , small amount of new bone formation; score 3 , intermediate amount of new bone; score 5 , and 
large amount of new bone formation. Scores were assigned at two different moments by two independent pathologists previously calibrated in a pilot project using the same methodology (interobserver agreement of $80 \%$ ) and blinded to group information.

Specimens from Group IV were submitted to SEM analysis to obtain a three-dimensional evaluation of the interface between bone tissue and implant material, and to describe the presence of structural abnormalities. Following sample metallization, specimens were analyzed using a Philips ${ }^{\circledR}$ XL20 scanning electron microscope (Eindhoven, The Netherlands) and evaluated using longitudinal cut planes of direct lateral views of the segments.

The Kruskal-Wallis and the Friedman nonparametric tests were used to evaluate the presence of significant differences between and within the groups, respectively. Significance was set at $5 \%$.

\section{Results}

Mean bone formation scores obtained at 30, 60, and 120 days for Groups I, II and III are presented in Table 1. No statistically significant differences were observed between the groups according to the Kruskal-Wallis nonparametric test $(\mathrm{p}<0.05)$.

TABLE 1 - Comparison of mean new bone formation scores obtained at different time points for the three groups (Kruskal-Wallis nonparametric test)

\begin{tabular}{cccc}
\hline Time point/group & Group & Mean & P \\
30 days & & & \\
I & & 3.8 & \\
II & & 3.4 & \\
III & 3.4 & 0.717 \\
60 days & & \\
I & 4.2 & \\
II & 4.2 & \\
III & 3.8 & 0.717 \\
120 days & & \\
I & 4.6 & \\
II & 4.2 & \\
III & 4.2 & 0.779 \\
\hline
\end{tabular}

The analysis of data collected within each group at different time points did not reveal statistically significant differences either according to the Friedman nonparametric test (Group I, $\mathrm{p}=0.459$; Group II, $\mathrm{p}=0.368$; Group III, $\mathrm{p}=0.459$ )

Microscopic images obtained 30 days postoperatively for Groups I, II, and III revealed the formation of immature bone tissue fully integrated into the bone cavity, with almost unnoticeable areas of bone marrow tissue. The histological sections showed fragments of bone tissue with scattered osteocytes and fine bone marrow canals (Figure 1A). Solutions of continuity compatible with the created bone defects and an irregular pattern of bone

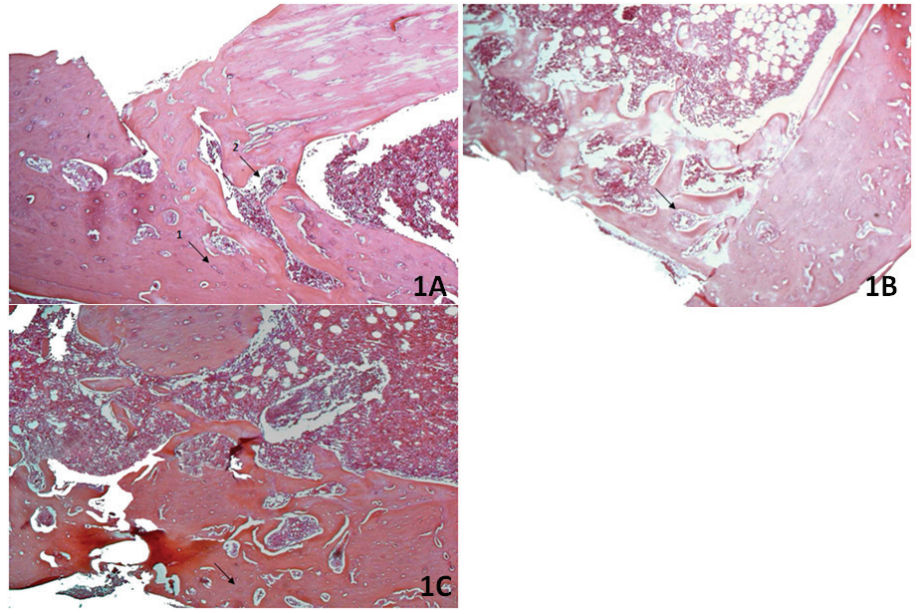

FIGURE 1 - Light microscopy findings at 30 days postoperatively, approximately 100x magnification, hematoxylin and eosin (HE) stain. A) Group I (AB), areas of new bone formation (1) and bone marrow tissue (2). B) Group II $(\alpha-\mathrm{TCP})$, cement particles in the newly formed bone trabeculae. C) Group III $(\alpha-\mathrm{TCP}+\mathrm{AB})$, area of intense new bone formation.

At 60 days postoperatively, there was absence of bone necrosis and presence of new bone formation in all samples (Figure 2).

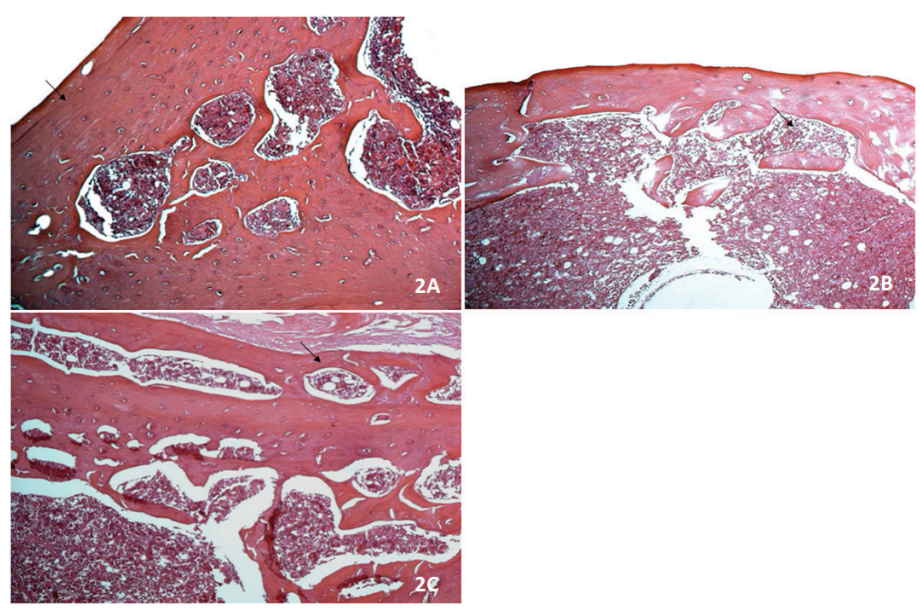

FIGURE 2 - Light microscopy findings at 60 days postoperatively, approximately 100x magnification, hematoxylin and eosin (HE) stain. A) Group I (AB), newly formed bone trabeculae with maturing characteristics (arrow). B) Group II ( $\alpha$-TCP), new bone formation among cement particles (arrow). C) Group III $(\alpha-\mathrm{TCP}+\mathrm{AB})$, area of new bone formation (arrow).

At 120 days, the images revealed a uniform pattern of trabecular bone in the interspace, evidencing bone tissue at the final stage of repair in all groups (Figure 3). 


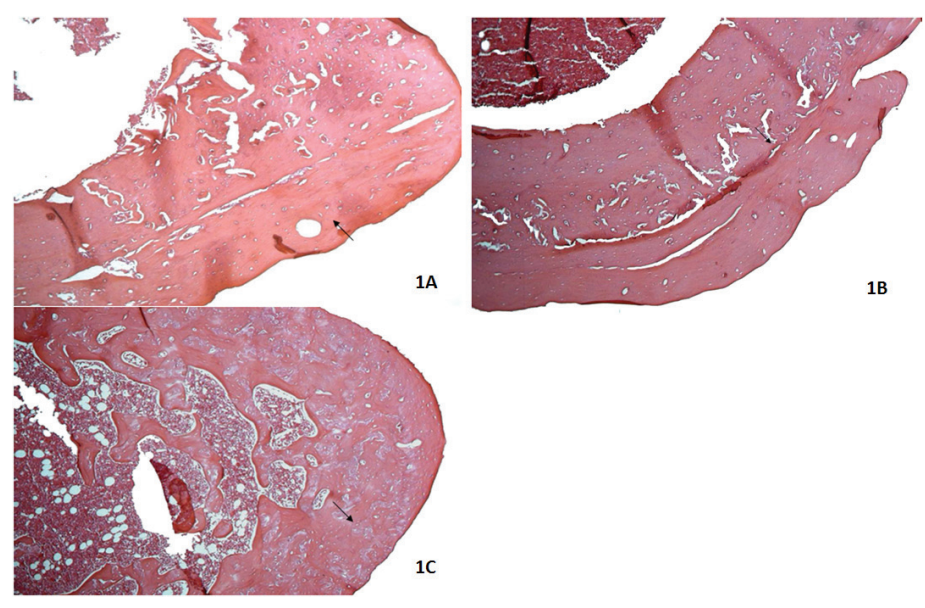

FIGURE 3 - Light microscopy findings at 120 days postoperatively, approximately 100x magnification, hematoxylin and eosin (HE) stain. A) Group I (AB), new bone formation (arrow). B) Group II ( $\alpha$-TCP), new bone formation among cement particles (arrow). C) Group III $(\alpha-\mathrm{TCP}+\mathrm{AB})$, area of new bone formation (arrow).

SEM analysis of Group IV specimens revealed absence of inflammatory response and incipient bone formation at 30 days postoperatively. A line could be observed at the interface between peripheral bone tissue and the implant (Figure 4A). At 60 days, the specimens revealed absence of inflammatory response and presence of mature bone tissue covering the defect. Initial vascular channels suggestive of bone remodeling and replacement of new immature bone with mature bone could be observed (Figure 4B). At 120 days postoperatively, the absence of inflammatory response was maintained, and it was possible to observe direct contact between the bone tissue and the implant, in addition to areas with several channels for blood vessels, which suggests intense new bone remodeling/formation (Figure 4C).
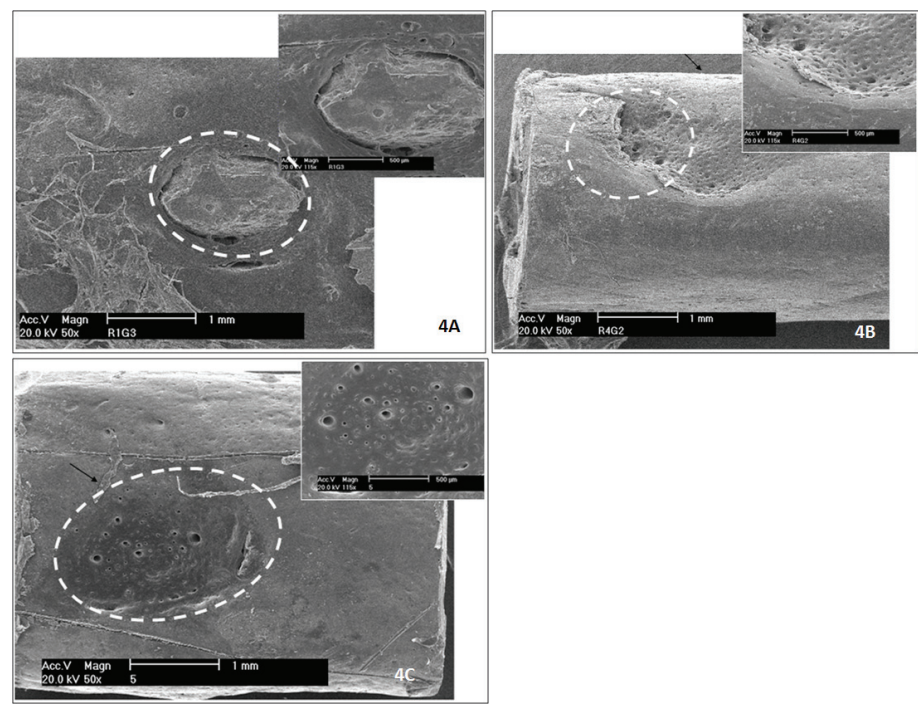

FIGURE 4 - Scanning electron microscopy findings (Group IV). A) Arrows indicate the interface between bone tissue and the $\alpha-\mathrm{TCP}+\mathrm{AB}$ implant, at 30 days. B) Arrow indicates direct contact between bone tissue and implant material, at 60 days. C) Arrow indicates areas suggestive of neovascularization within the implant material, at 120 days.
Comparative SEM analyses of Group IV specimens at 30,60 , and 120 days allowed to observe the osteoconductive properties of $\alpha$-TCP. The formation of new bone surrounding the implant material and the consequent resorption of this material prevented tissue dehiscence and allowed the cement to completely cover the defect, thus improving the cosmetic and functional characteristics of newly formed bone.

\section{Discussion}

The present study was designed to assess the biological behavior of $\alpha$-TCP and its ability to promote new bone formation. A mixture of $\alpha$-TCP and autogenous bone (AB) was used to investigate whether the combination of these two materials could either improve or preserve their individual characteristics and increase new bone formation when compared with their individual use alone. Our results clearly showed that $\alpha$-TCP has osteoconductive properties and promotes bone remodeling, with simultaneous replacement of bone through the normal osteoclasticosteoblastic coupling.

The biological behavior of CPC has been studied in vivo in several animal models ${ }^{13,14}$ with adequate results. Based on these reports, the present study used a dual-setting $\alpha$-TCP cement developed at the Laboratory of Biomaterials (Labiomat), UFRGS, Porto Alegre, Brazil2,9, in rats. Our findings confirmed those obtained previously.

AB grafts remain as the standard material for craniofacial skeletal reconstruction ${ }^{15,16}$. However, some important clinical limitations are associated with $\mathrm{AB}$, such as the need for a donor site, donor site morbidity, increased operative time, blood loss, additional cost, and limited availability ${ }^{1,15,17}$. In this context, alloplastic biomaterials have been increasingly investigated and considered as effective alternative bone substitutes. Among the alloplastic biomaterials currently used, calcium phosphate bioceramic seems to be the most biocompatible and well-tolerated option, a finding that was confirmed in the present study by the absence of statistically significant differences between Groups I, II, and III in terms of new bone formation.

Although the comparative analysis performed in our sample did not yield a statistically significant difference between the materials under analysis, a better organization of tissues adjacent to the graft was observed in Group I (AB). Inflammatory infiltrate and bone necrosis were absent in this group, and only one animal showed bone resorption.

The histological analyses also revealed absence of inflammatory response in all $\alpha$-TCP implants, which is in accordance with other studies designed to assess the biocompatibility of this material $1^{1,2,9,18}$. Moreover, the positive biocompatibility findings associated with $\alpha$-TCP were present at the three time points assessed. In fact, no bone necrosis and inflammatory infiltrate were observed in any of the study groups, probably due to the time periods chosen for assessment, which allows to speculate that this finding occurred independently of the type of material used. With regard to bone resorption, this finding was not observed in any of the groups.

Other possible explanations for the absence of inflammation and bone necrosis in our specimens include the 
maintenance of the aseptic chain and the use of constant irrigation during drilling. With regard to the first aspect, the fact that $\alpha$-TCP was sterilized by gamma radiation allowed the maintenance of the aseptic chain and avoided possible postoperative complications. In addition, the use of copious, profuse, continuous irrigation with saline solution $(\mathrm{NaCl} 0.9 \%)$ during drilling ensured a safe and unbiased histological analysis in terms of the detection of bone necrosis.

The results obtained by SEM analysis revealed increased vascularization, which resulted in intense new bone formation and a final integration between implant and bone, as reported by other authors ${ }^{19}$. Previous studies have shown that CPC implants can allow the ingrowth of bone tissue with functional haversian systems and facilitated osseointegration ${ }^{20}$. In our study, tubular structures suggestive of the presence of Havers and Volkmann channels were also observed.

Also, SEM images revealed the presence of osteoclastmediated resorption, allowing for the replacement of newly formed bone tissue with mature bone. These findings suggest that the cement acts as a temporary rather than a permanent bone tissue substitute, a behavior that is defined as osteoconductive. The speed of the osteoconductive process is strongly influenced by the implantation site, the type of CFC employed and the age of the recipient.

For the implant material to become adequately integrated with the bone tissue, it is desirable that its shape be maintained indefinitely. In the present study, one of the main difficulties encountered while handling $\alpha$-TCP was related to its solubility, which impaired adhesion at the implantation site whenever a high moisture content was presence due to contact with liquid materials (e.g. blood). This limitation was overcome with adequate aspiration and a dry surgical field, so as to prevent dislocation of the cement after its setting ${ }^{13}$.

\section{Conclusion}

The $\alpha$-TCP implant is effective alternative bone substitutes for the treatment of critical size bone defects, showing similarity to the autogenous bone on the resorption and presence of new bone formation.

\section{References}

1. Schmitz JP, Hollinger JO, Milam SB. Reconstruction of bone using calcium phosphate bone cements: a critical review. J Oral Maxillofac Surg. 1999;57:1122-6.

2. Biancon Filho LA, Primo BT, Gassen HT, Fontanella VRC, Silva Jr AN. Evaluation of optical density of bone defects filled with calcium phosphate cement and bioactive glass in rats. Acta Cir Bras. 2011;26(1). Available from URL: http://www.scielo.br/acb [Epub ahead of print]

3. Okada E, Maruyama Y, Hayashi A. Nasal augmentation using calcium phosphate cement. J Craniofac Surg. 2004;15:102-5.

4. Alves HL, Dos Santos LA, Bergmann CP. Injectability evaluation of tricalcium phosphate bone cement. J Mater Sci Mater Med. 2008;19:2241-6.

5. Jackson IT, Yavuzer R. Hydroxyapatite cement: an alternative for craniofacial skeletal contour refinements. Br J Plast Surg. 2000;53:24-9.
6. Sugawara A, Fujikawa K, Takagi S, Chow LC. Histological analysis of calcium phosphate bone grafts for surgically created periodontal bone defects in dogs. Dent Mater J. 2008;27:787-94.

7. Silva TSN, Primo BT, Silva Júnior AN, Machado DC, Viezzer C, Santos LA. Use of calcium phosphate cement scaffolds for bone tissue engineering: in vitro study. Acta Cir Bras. 2011;26(1). Available from URL: http://www.scielo.br/acb [Epub ahead of print]

8. Arisan V, Anil A, Wolke JG, Ozer K. The effect of injectable calcium phosphate cement on bone anchorage of titanium implants: an experimental feasibility study in dogs. Int J Oral Maxillofac Surg. 2010;39:463-8.

9. dos Santos LA, Carrodéguas RG, Rogero SO, Higa OZ, Boschi AO, de Arruda AC. Alpha-tricalcium phosphate cement: "in vitro" cytotoxicity. Biomaterials. 2002;23:2035-42.

10. Le Guehennec L, Goyenvalle E, Aguado E, Houchmand-Cuny M, Enkel B, Pilet P, Daculsi G, Layrolle P. Small-animal models for testing macroporous ceramic bone substitutes. J Biomed Mater Res B Appl Biomater. 2005;72:69-78.

11. Hollinger JO, Kleinschmidt JC. The critical size defect as an experimental model to test bone repair materials. J Craniofac Surg. 1990;1:60-8.

12. Takeda Y. Irradiation effect of low-energy laser on alveolar bone after tooth extraction. Experimental study in rats. Int $\mathrm{J}$ Oral Maxillofac Surg. 1988;17:388-91.

13. Kurashina K, Kurita H, Kotani A, Takeuchi H, Hirano M. In vivo study of a calcium phosphate cement consisting of a-tricalcium phosphate dibasic/tetracalcium phosphate monoxide. Biomaterials. 1997; 18:147-51.

14. Moraes PC, Padilha Filho JG, Canola JC, dos Santos LA, Macoris DG, Alessi AC, de Castro MB, Dória Neto FA. Biocompatibility of calcium phosphate cement implanted in radius of rabbits. Acta Cir Bras. 2004;19:351-9.

15. Ellis E 3rd, Messo E. Use of nonresorbable alloplastic implants for internal orbital reconstruction. J Oral Maxillofac Surg. 2004;62:873-81.

16. Kontio R. Treatment of orbital fractures: the case for reconstruction with autogenous bone. J Oral Maxillofac Surg. 2004;62:863-8.

17. Silva RA, Fagundes DJ, Silva ACMBA, Sisti KE, Carvalho TMMB, Silva DN. Effect of anti-inflammatory agents on the integration of autogenous bone graft and bovine bone devitalized matrix in rats. Acta Cir Bras. 2008;23(2):140-8. Available from URL: http://www.scielo.br/acb

18. Miyamoto Y, Ishikawa K, Takechi M, Yuasa M, Kon M, Nagayama M, Asaoka K. Non-decay type fast-setting calcium phosphate cement: setting behaviour in calf serum and its tissue response. Biomaterials. 1996; 17:1429-35.

19. Moghadam HG, Sándor GK, Holmes HH, Clokie CM. Histomorphometric evaluation of bone regeneration using allogeneic and alloplastic bone substitutes. J Oral Maxillofac Surg. 2004;62:202-13.

20. Takagi S, Chow LC. Formation of macropores in calcium phosphate cement implants. J Mater Sci Mater Med. 2001;12:1359

\section{Correspondence:}

Dr. Aurelício Novaes Silva Júnior

Conflict of interest: none Financial source: none

Universidade Luterana do Brasil

Faculdade de Odontologia -

Departamento de Pós-Graduação

Rua Farroupilha, 8001 - Prédio 59

92425-900 Canoas - RS Brasil

Phone/Fax: (55 51)9229-8277

aurelicio.junior@uol.com.br
Received: September 15, 2010

Review: November 18, 2010

Accepted: December 17, 2010 